\title{
MATING SEASONALITY IN CASTRATED MALE RHESUS MONKEYS
}

\author{
RICHARD P. MICHAEL AND MARGO I. WILSON* \\ Department of Psychiatry, Emory University School of Medicine, and \\ Georgia Mental Health Institute, Atlanta, Georgia 30306, U.S.A.
}

(Received 23rd Fuly 1974)

Many species of non-human primates have relatively discrete breeding seasons. Under free-ranging conditions, rhesus monkeys (Macaca mulatta) mate most frequently during November to January in North India (Prakash, 1962; Southwick, Beg \& Siddiqi, 1965; Lindburg, 1971), during September to November on Cayo Santiago (Conaway \& Koford, 1964; Loy, 1971) and during November to December at La Parguera in the Caribbean (Vandenbergh \& Vessey, 1968). The mating season of rhesus monkeys in Australian zoos (Hartman, 1932) and on Ilha do Pinheiro, near Rio de Janeiro at latitude $22^{\circ} \mathrm{S}$, is displaced by approximately 6 months, suggesting that the photoperiod provides a stimulus. Under free-ranging conditions on Cayo Santiago, males undergo testicular regression and are sexually inactive between February and May, at a time when females are pregnant or lactating (Conaway \& Sade, 1965). More recent studies (Plant, Zumpe, Sauls \& Michael, 1974) have demonstrated an annual rhythm in the plasma testosterone of male rhesus monkeys maintained in the laboratory that corresponded with the annual changes in spermatogenesis and testicular size described in feral males. When these data are put together, one is led to the view that seasonal, exteroceptive factors, which activate the testes through the anterior pituitary, result in increasing plasma levels of androgens that, in turn, mediate the long-term changes in sexual activity. In a relatively controlled laboratory environment, however, Michael \& Keverne (1971) found that rhesus males, paired with intact females whose oviducts had been ligated to prevent pregnancy, showed a peak in ejaculatory activity in December followed by a decline between February and May: thus, the long-term behavioural rhythm of males in the laboratory was remarkably similar to that occurring in the natural habitat in North India (Text-fig. 1). The data suggested the possible existence of an annual rhythm in sexual potency that was, at least in part, independent of major environmental variables.

This proposition was investigated in two male rhesus monkeys over a period of 21 months during 822 tests carried out in London. Each male was paired with two females, making four paired combinations. Animals were obtained from North India, and housed in individual cages together in the same animal room, the temperature of which was maintained by air conditioning between 65 and $70^{\circ} \mathrm{F}$. Lighting was controlled by a time-clock giving a 14-hr day between

* Present address: Department of Psychology, University of Toronto, Ontario, Canada. 


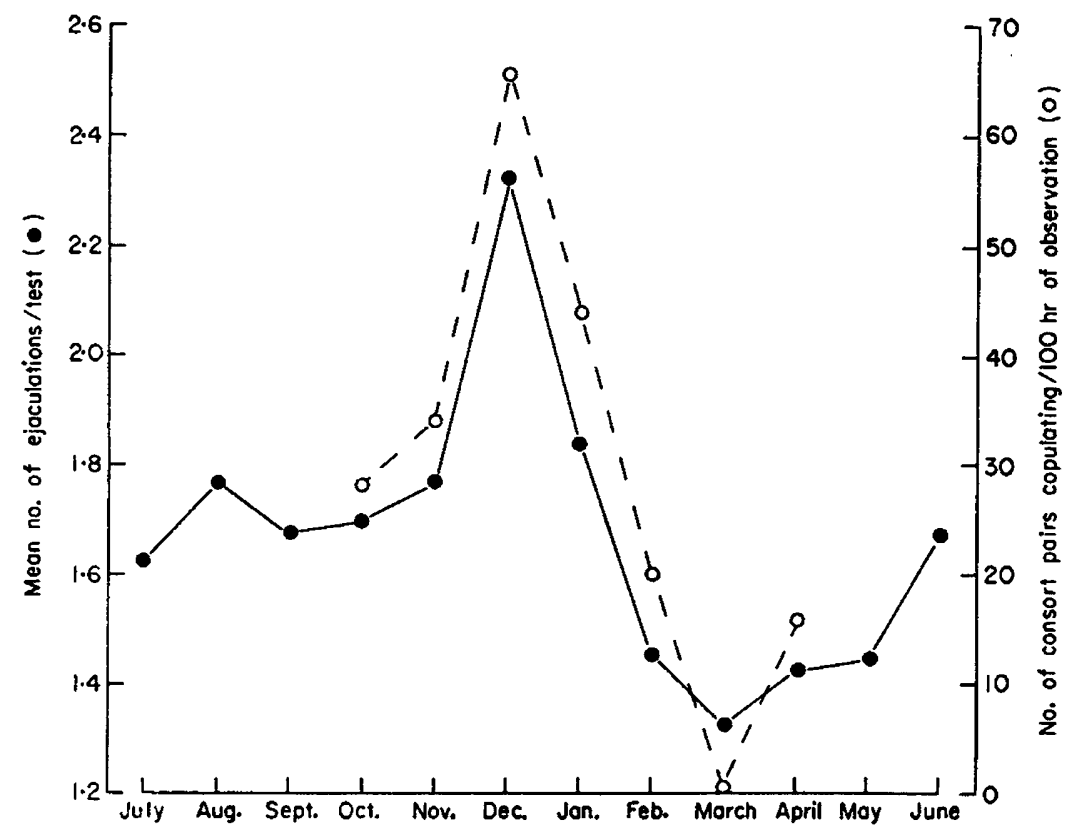

TExT-FIG. 1. The number of consort pairs of rhesus monkeys observed copulating during different months in the wild in North India (O, Southwick et al., 1965) compared with the ejaculatory activity of intact rhesus males (e) maintained under laboratory conditions in London (1156 tests) (Michael \& Keverne, 1971). There is a remarkable similarity between the timing of the annual changes in behaviour of both groups, with wellcircumscribed increases in sexual activity in December.

06.15 and 20.15 hours. This was increased by natural daylight by up to $2 \mathrm{hr}$ between mid-June and mid-July. Free access to food and water was allowed. Males were castrated and received testosterone propionate, $2 \mathrm{mg}$ intramuscularly per day throughout the study. As previously shown, this fully restores plasma levels (Michael, 1972). Females were ovariectomized and received oestradiol monobenzoate, $5 \mu \mathrm{g}$ subcutaneously per day throughout the study. Thus, both males and females were subjected to constant hormonal stimulation. Behavioural tests were conducted from behind one-way vision mirrors in special observation cages to which first the male and then the female of the pair was introduced (Michael, Saayman \& Zumpe, 1968). The duration of each test was $1 \mathrm{hr}$ and testing was carried out 5 days a week. The order in which the animals were tested was kept constant. Particular attention is given here to the mean numbers of ejaculations/test, and Text-fig. 2 shows that both males exhibited wellmarked annual rhythms in ejaculatory performance with both of their partners. The onset of this activity was similar to that observed in intact males either in their natural habitat or in a laboratory environment. In castrates receiving testosterone replacement, the decline in sexual activity occurred somewhat later in the year and changes seemed less well-defined than in the two groups with intact gonads (Text-fig. 1).

These results, which are essentially preliminary ones, do not fit in easily with the current state of knowledge, and pose certain difficulties for understanding 


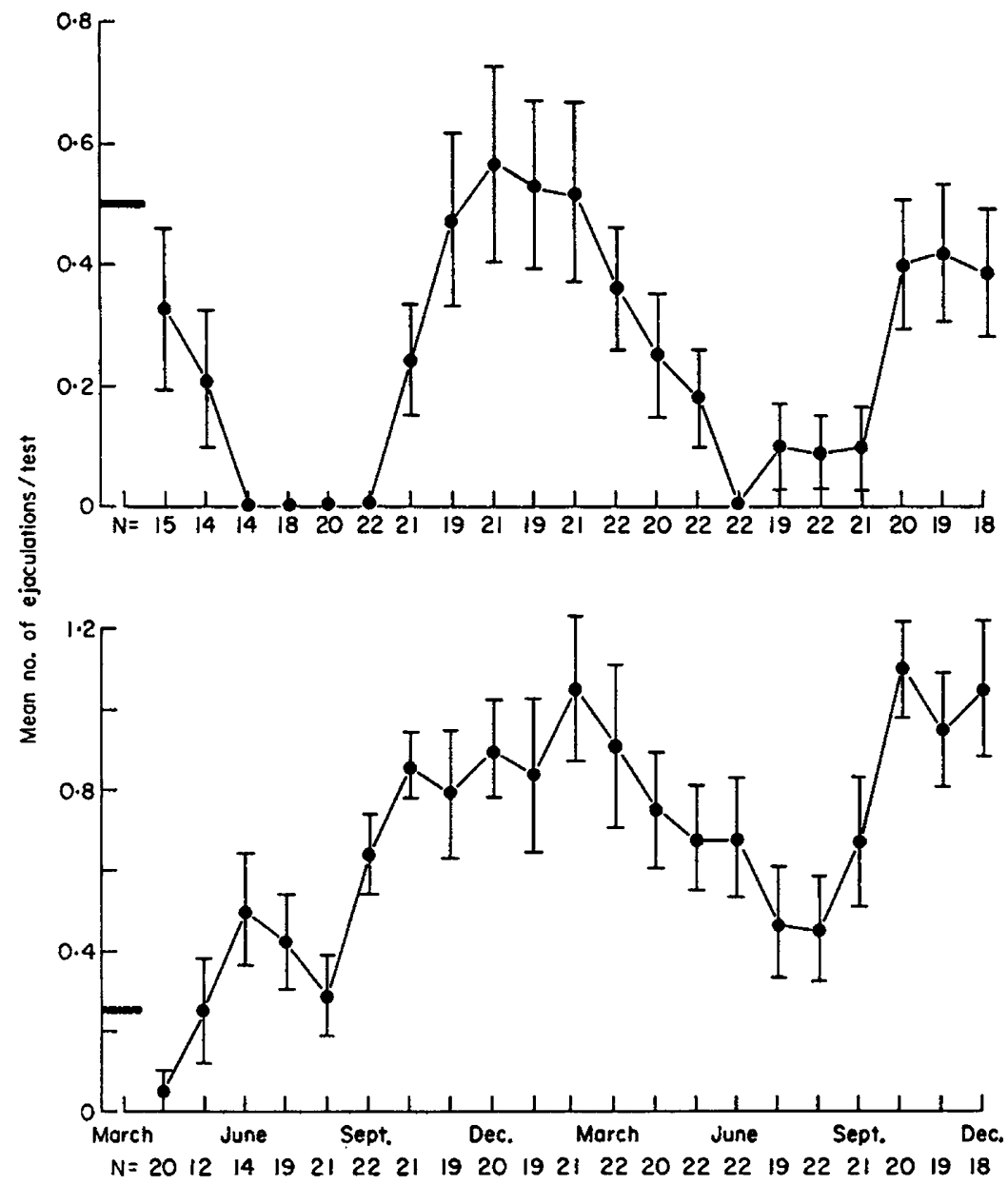

TexT-FIG. 2. Annual changes in the ejaculatory activity of two castrated, testosteronetreated rhesus males each paired with two ovariectomized, oestrogen-treated partners (four pairs, 822 tests). Despite the absence of gonads and the constant hormonal stimulation, there were annual changes in male sexual behaviour resembling, but less circumscribed than, those in intact groups. $\mathrm{N}=$ number of tests. Vertical bars represent the S.E.M.

the neuroendocrine mechanisms that determine sexual potency in male primates and the annual rhythm it undergoes. There are good data indicating that castration results in a decline in ejaculatory performance and that testosterone replacement helps to restore it (Michael, 1972; Phoenix, Slob \& Goy, 1973), but a time interval of several weeks is needed for effects to become established. Although the male gonad is obviously involved, changes in plasma testosterone levels cannot be directly related to changes in sexual potency ( $R$. P. Michael, unpublished observations).

Furthermore, red deer (Cerous elaphus) stags may mate with receptive females up to 5 months after the seasonal peak of testicular androgen (Lincoln, Youngson \& Short, 1970). It seems that the rôle of testosterone may be a facultative 
one, a threshold level being needed above which the precise plasma concentration becomes irrelevant. Nevertheless, in the detailed study of four pairs of rhesus monkeys described here, the males demonstrated a clear-cut annual behavioural rhythm that could not have been mediated through the gonads. When compared with intact groups, annual fluctuations in the sexual activity of gonadectomized animals seemed to be less well circumscribed, reflecting perhaps the lack of any exteroceptive stimuli acting through the testes.

Many factors remain to be considered. We know little about any seasonal changes in the plasma binding and in the plasma clearance of androgens that may affect the availability of metabolically active hormone, and we have no information about the way in which changes in plasma concentrations may be reflected in the brain and other target tissues. Seasonal changes in potency are certainly not trivial. They represent a major change in the level of male sexual performance, and our current view is that these behavioural changes may depend on an alteration in the threshold of a brain mechanism that is not mediated through the gonad.

This work was supported by grants from the Medical Research Council (U.K.), The Foundations' Fund for Research in Psychiatry and NIMH (Grant MH19506) which are gratefully acknowledged. Miss Jennifer Waller is thanked for her assistance.

\section{REFERENCES}

Conaway, C. H. \& Koford, C. B. (1964) Estrous cycles and mating behaviour in a free-ranging band of rhesus monkeys. F. Mammal. 45, 577-588.

ConaWAy, C. H. \& SADE, D. S. (1965) The seasonal spermatogenic cycle in free ranging rhesus monkeys. Folia primat. 3, 1-12.

Hartman, C. G. (1932) Studies in the reproduction of the monkey Macacus (Pithecus) rhesus, with special reference to menstruation and pregnancy. Contrib. Embryol. 23, 1-161.

Lincoln, G. A., Youngson, R. W. \& Short, R. V. (1970) The social and sexual behaviour of the red deer stag. 7. Reprod. Fert., Suppl. 11, 71-103.

LindBuRG, D. G. (1971) The rhesus monkey in North India: an ecological and behavioral study. In Primate Behavior: Developments in Field and Laboratory Research, Vol. 2, pp. 1-106. Ed. L. A. Rosenblum. Academic Press, New York.

Loy, J. (1971) Estrous behavior of free-ranging rhesus monkeys (Macaca mulatta). Primates, 12, 1-31.

MichaEL, R. P. (1972) Determinants of primate reproductive behaviour. In The Use of Non-Human Primates in Research on Human Reproduction, pp. 322-361. Eds. E. Diczfalusy and C. C. Standley. WHO Research and Training Centre on Human Reproduction, Karolinska Institutet, Stockholm.

Michaed, R. P. \& KeVerne, E. B. (1971) An annual rhythm in the sexual activity of the male rhesus monkey, Macaca mulatta, in the laboratory. F. Reprod. Fert. 25, 95-98.

Michael, R. P., SAayman, G. S. \& Zumpe, D. (1968) The suppression of mounting behaviour and ejaculation in male rhesus monkeys (Macaca mulatta) by administration of progesterone to their female partners. F. Endocr. 41, 421-431.

Phoenix, C. H., Slob, A. K. \& Goy, R. W. (1973) Effects of castration and replacement therapy on sexual behavior of adult male rhesuses. F. comp. physiol. Psychol. 84, 472-481.

Plant, T. M., Zumpe, D., Sauls, M. \& Michael, R. P. (1974) An annual rhythm in the plasma testosterone of adult male rhesus monkeys maintained in the laboratory. F. Endocr. 62, 403-404.

Prakash, I. (1962) Group organisation, sexual behaviour and breeding season of certain Indian monkeys. Jap. 7. Ecol. 12, 83-86.

Southwick, G. H., BeG, M. A. \& Siddrer, M. R. (1965) Rhesus monkeys in North India. In Primate Behavior, pp. 111-159. Ed. I. DeVore. Holt, Rinehart \& Winston, New York.

VANDENBERGH, J. G. \& VESSEY, S. (1968) Seasonal breeding of free ranging rhesus monkeys and related ecological factors. F. Reprod. Fert. 15, 71-79. 